\title{
Outcome based learning of optics in schools
}

\section{Esakkimuthu Raju, Badrinath Vadakkapattu Canthadai, Kumar Ravi}

M. Esakkimuthu Raju, Badrinath Vadakkapattu Canthadai, Kumar Ravi, "Outcome based learning of optics in schools," Proc. SPIE 9188, Optics Education and Outreach III, 91880R (15 September 2014); doi: $10.1117 / 12.2061998$

SPIE Event: SPIE Optical Engineering + Applications, 2014, San Diego, California, United States 


\title{
Outcome Based Learning of Optics in schools
}

\author{
M. Esakkimuthu Raju*a, Badrinath Vadakkapattu Canthadai ${ }^{\mathrm{a}}$, Kumar Ravi ${ }^{\mathrm{a}}$, \\ ${ }^{a}$ Dept. of Physics, Vidya Jyothi Institute of Technology, Hyderabad, India \\ esakki.raju@gmail.com
}

\begin{abstract}
This paper describes the work of some SPIE student chapter members to create interest in students on optics by teaching students in upper primary schools in and around college premises on fundamental concepts of light such as reflection, refraction, diffraction, etc. This paper discusses about how the outcome based education (OBE) is helpful in learning optics interesting rather than the traditional way of learning. In order to achieve this, students are divided into groups and conducted a workshop. Student learning outcomes were assessed at the end of the program. The program is useful to us to improve our understanding of how students learn light - related principles and provide evidence of the learning outcomes on the subject. Our research established that students in every classroom learned optics concepts, uncovered student ideas about optics, and identified ways to support and supplement the curriculum for use in classrooms.
\end{abstract}

Keywords: Outcome based education, optics, photonics, outcome

\section{INTRODUCTION}

Physics is perceived as a difficult course for student from secondary school to university and also for adults in graduate education. It is well known that both high school and college students find Physics difficult ${ }^{1}$. Optics is one of the branches of Physics which deals with study of nature, propagation and properties of light. Light, Optics and Photonics have a crucial importance in our lives and to the prospects of development of our world with breathtaking developments in many different fields ${ }^{2}$. Due to the emerging nature of the optics industry, demand for those with optics expertise is very high and is projected to increase as more ways of applying optics in technology are discovered.

Without providing the best possible education for every student, to develop the skills needed to responsibly contribute to an advanced industrial society, the Nation will be at risk of losing its leadership position in shaping and defining our own futures ${ }^{3}$.

We have observed that most of the students of middle school ignore or give less importance to the branch "Optics' Therefore, it is required to motivate and create interest in this subject in children from school onwards. The teaching methodology plays an important role in bringing up the abilities of students ${ }^{4}$.

\subsection{Outcome Based Education (OBE)}

In the Traditional teaching method, classroom settings are teacher-centered where the teacher often talks at the pupils instead of advancing them to interact, ask queries or make them interpret the lesson entirely. Traditional teaching methods like lectures and dictations, rote memorization and little interaction have some disadvantages in the classroom often leave students less attentive and less engaged. Students depend on memorization without having a complete apprehension of the issue and have no chance to interact with their classmates or their instructor.

In contrast, the recently introduced outcome based training known as OBE is to facilitate desired changes within the learners, by increasing knowledge, acquiring skills and/or positively influencing attitudes, values and judgment. OBE embodies the idea that the best way to learn is to first determine what needs to be achieved. In OBE, once the end goal (product or outcome) has been determined the strategies, processes, techniques, and other ways and means can be put into place to achieve the goal.

Optics Education and Outreach III, edited by G. Groot Gregory, Proc. of SPIE Vol. 9188,

91880R (c) 2014 SPIE · CCC code: 0277-786X/14/\$18 · doi: 10.1117/12.2061998 
Our idea is to implement the OBE in Optics in a rural school to create interest in learning and to develop certain skills among the students. The target group consists of middle school students who were divided into groups for performing activities to build up teamwork among the students.

Table 1. Comparison between Traditional Education and Outcome Based Education

\begin{tabular}{|l|l|}
\hline \multicolumn{1}{|c|}{ Traditional Education } & \multicolumn{1}{c|}{ Outcome Based Education } \\
\hline Passive learners & Active learners \\
\hline Teacher - centered instruction & Student - centered instruction \\
\hline Content based/broken into subjects & $\begin{array}{l}\text { Integration knowledge, learning relevant/ connected } \\
\text { real life situations }\end{array}$ \\
\hline Main objective is High test scores, high grades & $\begin{array}{l}\text { Learning, retention, accumulation of valuable } \\
\text { knowledge \& skills }\end{array}$ \\
\hline Rote learning & Critical thinking, reasoning, reflection \& action \\
\hline Assessment process - exam \& grade driven & Continuous assessment \\
\hline Teachers/trainers responsible for learning & Learners take responsibility for their learning \\
\hline Emphasis what teacher hopes to achieve & $\begin{array}{l}\text { Emphasis outcomes - what learner becomes } \\
\text { \& understands }\end{array}$ \\
\hline
\end{tabular}

\section{METHODOLOGY}

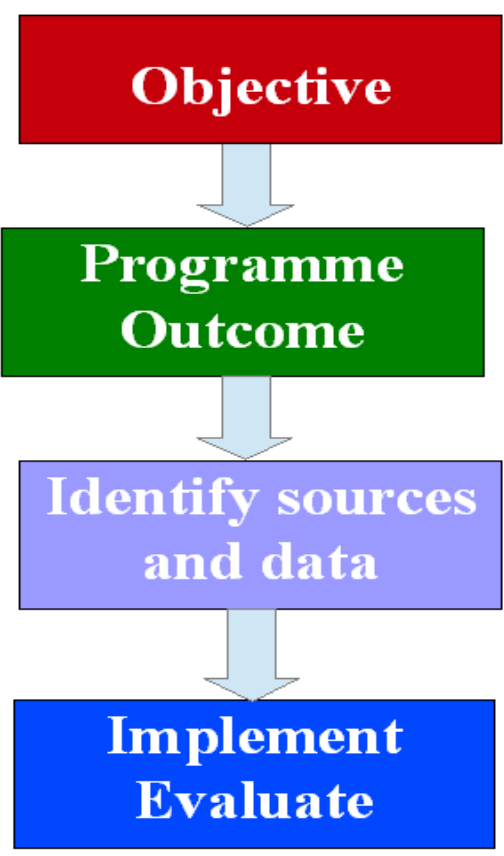

Fig. 1 Represents the flow chart of outcome based education 
We have implemented the method of Outcome based education in learning optics in schools. For this, we have selected two schools to study the effectiveness of learning.

\subsection{Objective}

The main objective is to enable the students to learn the basics of light such as illumination, propagation, reflection and refraction and also to create an interest in learning further.

\subsection{Program Outcome}

At the end of this program, students will be able

- To design a model by themselves which will explain the illumination of light, linear propagation of light and sources of light

- To understand the properties of light (reflection, refraction and dispersion)

- To categorize the objects based on transmission of light (transparent, translucent and opaque)

Apart from these specific learning outcomes, the cross-field outcome included that learners should be able to communicate effectively using the terminology.

\subsection{Sources and Data}

A set of simple experiments was designed to motivate the students to learn basic concepts of light. We prepared a box provided with a bulb and an object in the corner. The students were asked to look inside the box through a hole with and without light on. Then the students were called for a few questions to attain them to infer what illumination is? They were also asked to tell some other examples to demonstrate the same concept (Light is essential for vision). They were also asked to discuss in the groups to realize the day and night vision in real world situations.

Materials such as plane mirrors (reflection), cardboard with holes (linear propagation of light), Water tank (refraction), laser light, ordinary torch lights (sources of light), transparent sheets (object: Transparent to light), oil paper (Object: Translucent), card boards (Object: Opaque), papers (to prepare the designs), batteries, connecting wires, LEDs were used for demonstration by the SPIE student chapter members. The students were provided with KHET - a laser game kit, given by SPIE to show that learning optics is fun.

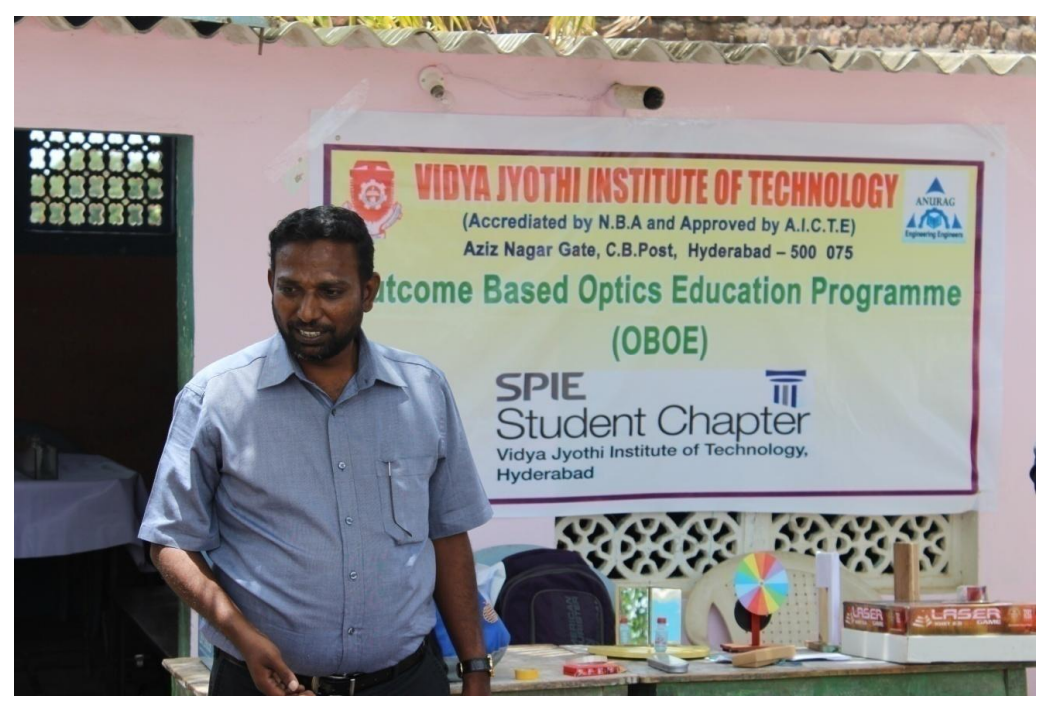

Fig. 2 A brief introduction being given to the students 


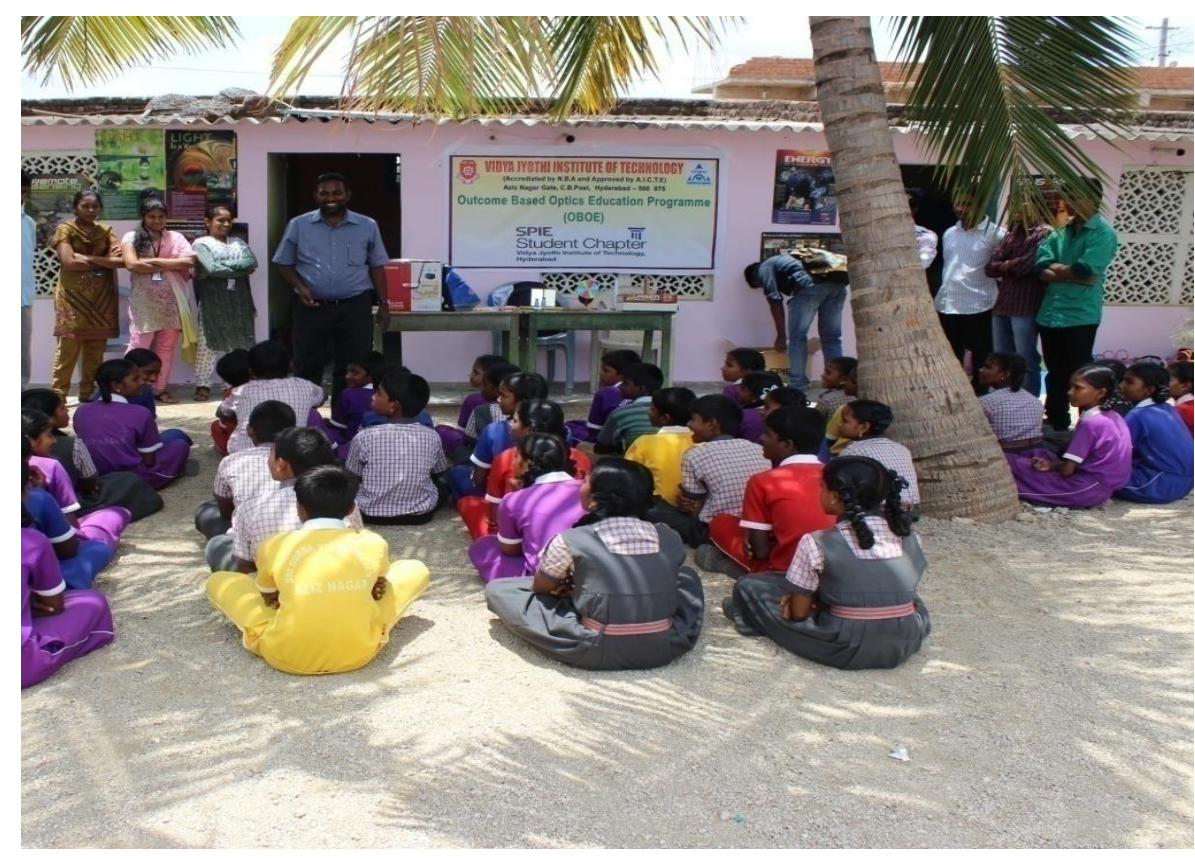

Fig. 3 Students listening with keen interest

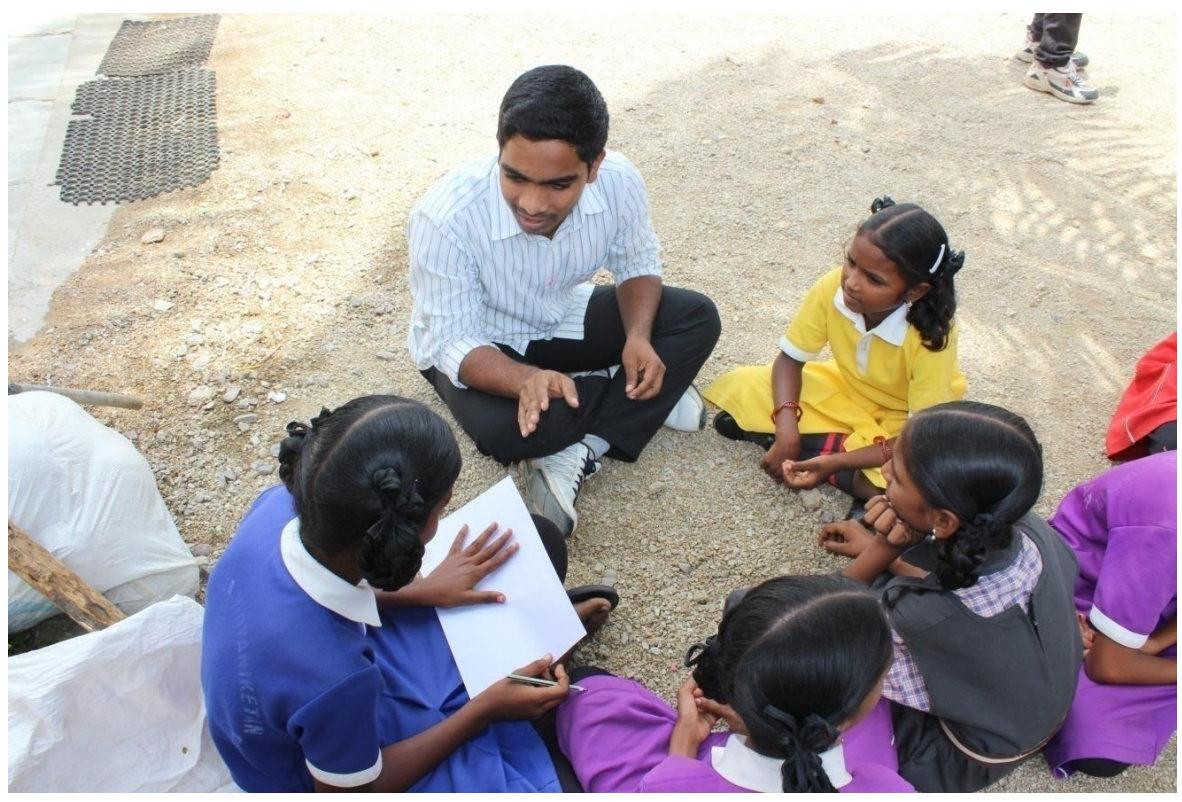

Fig. 4 An SPIE student member interacting with the students 


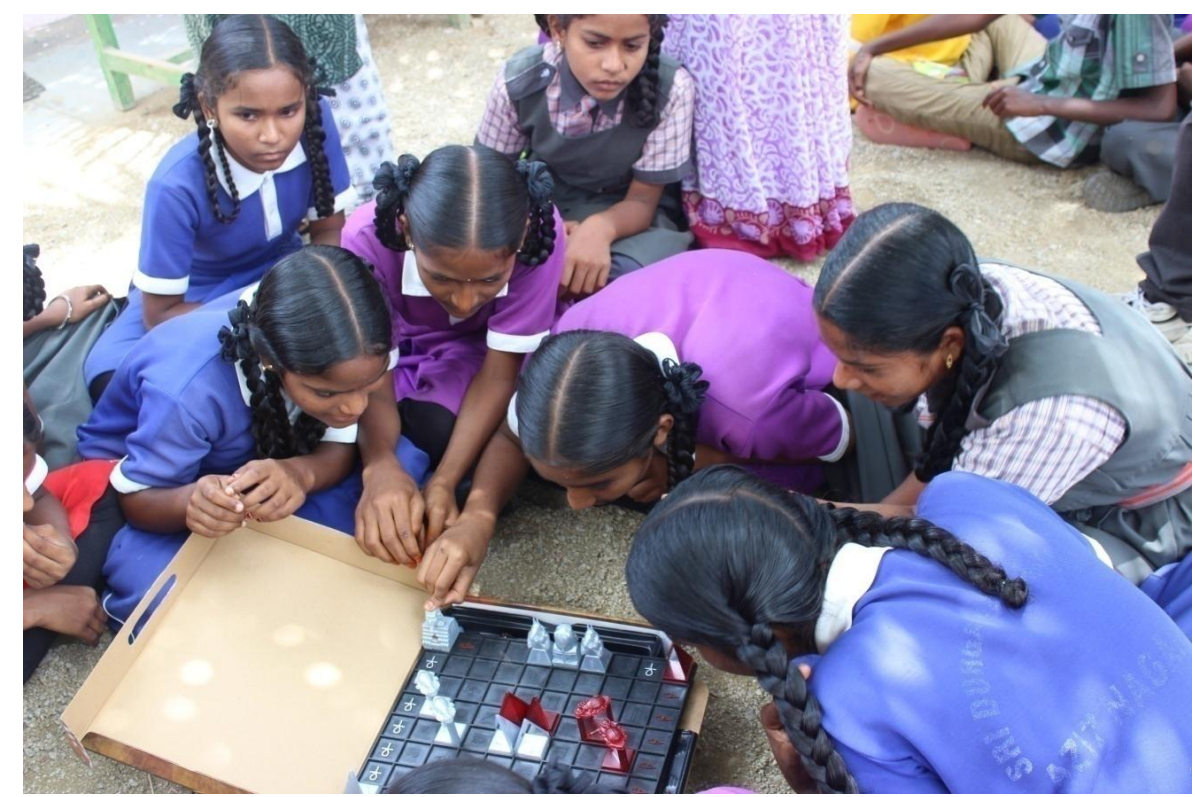

Fig. 5 Students engrossed in playing the laser game

\section{RESULT}

We have conducted a pre survey and post survey to assess the effectiveness of learning in Optics based on OBE. We have found that there is an overall development among the students in the learning process. The students are able to understand the basic properties of light. All the students were successfully able to demonstrate the concepts by themselves. They also wrote a summary of what they have learned. This was used to assess how well the students were able to understand and explain it in their own words. The results of individual students learning are shown is Fig.6.

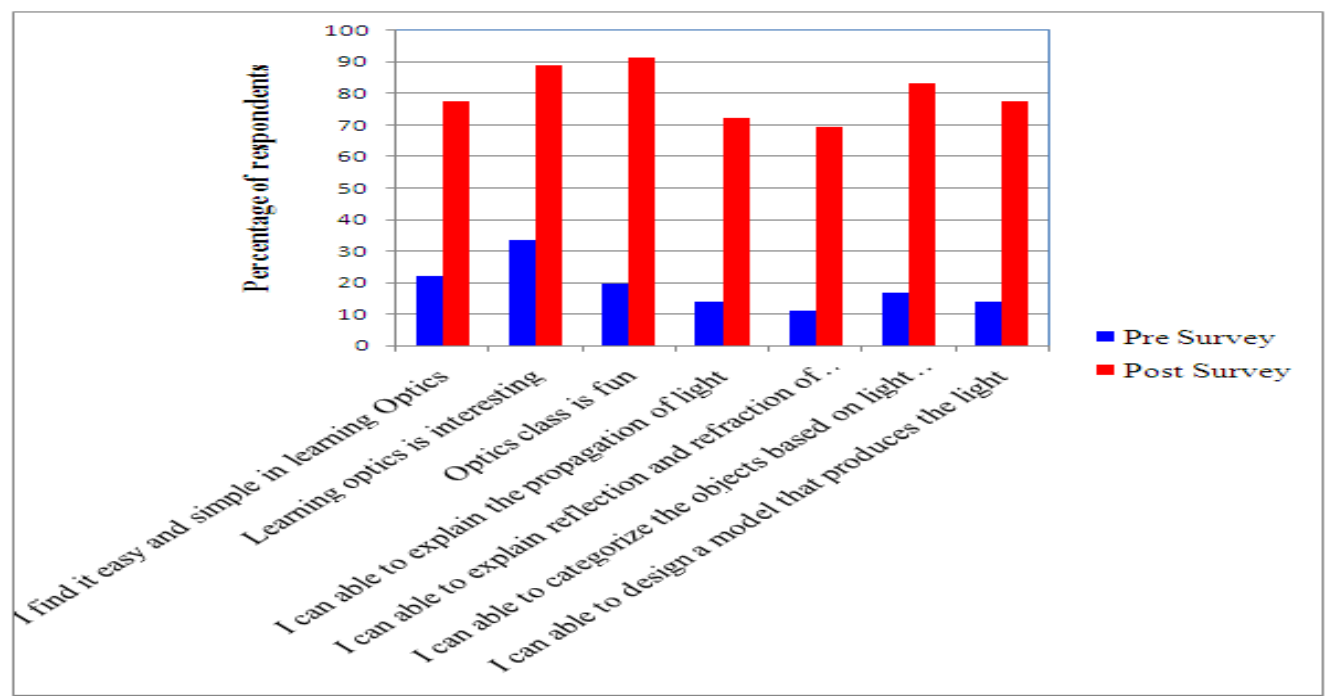

Fig. 6 Pre and Post survey results of Outcome Based Optics Education Program 


\section{CONCLUSION}

We have successfully gone through the learning methods based on OBE to actively involve all the students to enhance arousal and makes performance more effective. The program is taken in a way that helps the students to achieve the intended learning outcomes and engage them in these learning activities through the instructional procedure. All the students were actively participated in the activities individually and in groups. The students were quickly learned how to design and demonstrate the concepts of light. Advanced learning methods such as OBE are useful to produce a more effective, fun and interactive learning experience.

\section{REFERENCES}

[1] Olusola, Olasimbo O., , Rotimi, C.O., Attitudes of Students towards the Study of Physics in College of Education Ikere, Ekiti, Ekiti State, Nigeria, , American International Journal of Contemporary Research, Vol. 2 No. 12, (2012).

[2] Debnath D., Barthakur N. K., Baruah R.S. \& Goswami P. K., , Problems of Teaching Optics in Middle School: A Survey in Batadraba Education Block of Nagaon District, Assam, India, , International Journal of Scientific and Research Publications, Volume 2, Issue 8, (2012).

[3] Optics Education - A Blueprint for the 21st Century, A project of Optical Society of America and SPIE--The International Society for Optical Engineering, (2001).

[4] Mary J. Leonard ., Ryan M. Hannahoe ., Gustave E. Nollmeyer ., Joseph A. Shaw ., Teaching and learning geometric optics in middle school through the Turning Eyes to the Big Sky project, Optical Engineering 52(6), 069001 (2013). 